Daniela Pinheiro Mestranda em Artes Visuais, Unicamp linha de pesquisa poéticas visuals e processos de criação, artişa multimín jornalista, Bachare

em fotografia pelo SENACISP com Cultura, UFRGS.

Professor do

Instituto de Artes

da Unicamp -

Estadual de

Campinas.

Coordenado

do Programa de

Pós-graduação de

Artes Visuais (2015

2017). Doutorado

em Comunicação

e Semiótica

pela Pontifícia

Universidade

Catolica de São

Paulo (1997)

\section{Experimentações com os cianótipos: uma relação com a matéria}

\section{Experimentations with Cianotypes:} $A$ relation with matter

Resumo: Este artigo faz parte do processo criativo da pesquisa de mestrado em desenvolvimento no programa pos graduação em Artes Visuais da Unicamp. Interessa-me abrir espaço para outros diálogos com a fotografia, expandindo o registro documental inicial da imagem em busca de uma poética visual por meio da experimentação através do processo histórico de fotografia chamado cianótipo. Pretende-se com isso ressignificar esses registros, fazendo emergir novos discursos visuais por meio do contato com a materialidade do referido processo. A pesquisa, que é teórica e experimental já começa a apresentar resultados iniciais destacando questionamentos que serão descritos neste artigo.

Palavras-chave: Cianótipo; Fotografia; Tempo; Memória; Processo.

Abstract: This article is part of the creative process of the master's research being developed at the Postgraduate Program in Visual Arts of Unicamp, Brazil My interest is to open up the space for other dialogues with photography, expanding the initial documentary aspect of the image as record toward visual poetics through experimentation with the historical photographic process called cyanotype. The aim is to re-signify these records, giving rise to new visual discourses through thentact with the materiality of the cyanotype process. The research is theoretica and conpe wimental therefore, we presente initial results and highlight issues in this article.

Keywords: Cyanotype: Photography: Time: Memory: Process.
A fotografia, ao longo de sua história, buscou o registro de um instante, com a intenção de estabelecer uma relação de proximidade física com o mundo real. O recorte da "realidade" executado pela fotografia, se insere em uma tradição que vem desde o renascimento e reforça o direcionamento da maneira como percebemos uma imagem. A imagem fotográfica pode adquirir vários outros significados se, a partir desse esquema fundamental, tentarmos seguir os inúmeros caminhos que existem potencialmente na própria fotografia. Pode-se ir além, aprofundando, pesquisando novos temas e desvendando novas relações.

Diante dos procedimentos do fazer fotográfico através do processo artesanal de fotografia, como o cianótipo, é possível perceber que a fotografia é um campo experimental capaz de produzir novos discursos visuais através de sua materialidade específica. O processo de cianotipia é uma técnica fotográfica artesanal inventada em 1842 pelo astrônomo e químico inglês Sir John Herschel e não se baseia nos sais de prata, mas na sensibilidade à luz ultravioleta de determinados sais de ferro (ferricianeto de potássio e citrato de ferro amoniacal) A impressão acontece por foto - contato, quando se emulsiona os químicos na superfície e colocam-se objetos ou negativos para expor na luz ultravioleta ou no sol.

O processo do cianótipo permite a participação do autor em todas as etapas de criação, interferindo nos resultados das escolhas através da preparação dos químicos, da gestualidade com o pincel, produção do negativo, tempo de exposição e revelação; resultando em uma linguagem visual que o fotógrafo produz "de acordo com suas próprias regras, cria novos seres, gera experiências visuais, constrói." (MONFORTE, 1997, p.12). Segundo Rouillé (2009), a intervenção direta da mão do fotógrafo na matéria e o retorno às práticas artesanais de fotografia são vistos pelo fotógrafo, como um respiro frente a uma profissão submetida às duras leis do mercado, da rentabilidade e do 
lucro. De outra parte, Flusser (2002), defende que o criador é aquele que penetra e compreende a finalidade do aparelho, experimenta com as regras já estabelecidas, inventa o seu processo e não cumpre um programa.

Para esse pensador, o fotógrafo "só pode fotografar o que é fotografável, isto é, o que está inscrito no aparelho" (FLUSSER, 2002 p.37), assim não existe muito espaço para criação. Flusser (2002) não fala em criatividade, mas sim em fotos informativas, não redundantes, e nesse sentido se aproxima do conceito de criação. Mas isso é impossível para o fotógrafo, "a não ser que deixe de fotografar e passe a funcionar na fábrica que programa aparelhos".Também temos fotógrafos que "tentam, conscientemente, obrigar o aparelho a produzir imagem informativa que não está em seu programa”. (Ibid., p. 84).

Uma forma de ultrapassar o programa é introduzindo novos materiais e procedimentos na produção fotográfica, é isso que exploramos nesta pesquisa, centrada na cianotipia e na forma como como ela permite experimentações. Os contextos das produções e as intervenções antes e durante o fazer importam enquanto elementos significativos para o trabalho, que não se encerra no ato de fotografar. Acreditamos em uma fotografia que coloca ênfase no fazer e incorpora as etapas processuais de sua produção; uma fotografia experimental, contaminada, híbrida, criativa, expandida, entre outras tantas denominações, enfatizando a importância dos processos de criação, "trata-se de uma fotografia contaminada pelo olhar, pela existência de seus autores e concebida como ponto de interseção entre as mais diversas modalidades artísticas" (CHIARELLI, 2002, p.115).

A principal função da fotografia expandida seria desafiar os paradigmas impostos pelo signo fotográfico tradicional. Uma fotografia que subverte a questão de pura representação, devendo ser consideradas todos os tipos possíveis de manipulação e interferência na imagem. Para Müller-Pohle (1985), fazer fotografia pressupõe uma série de intervenções em diferentes momentos: no ato da tomada fotográfica (interferências no objeto fotografado, no aparelho fotográfico, no negativo ou cópia), na distribuição e na recepção da imagem.

Segundo Fernandes Jr (2006), a fotografia expandida se liberta das amarras do fazer fotográfico tradicional, deixando de ser documento fiel da realidade para se tornar a percepção de novos tempos e espaços, onde é realçado o processo de criação, não se podendo ignorar o fotógrafo e o seu olhar subjetivo.

Nesta pesquisa o processo criativo parte de registros fotográficos digitais, realizados por mim, das Figueiras nas ruas de areia da Praia do Laranjal, na cidade de Pelotas, Rio Grande do Sul. Em um segundo momento, existe a experimentação com a técnica de cianotipia, que transforma fisicamente essas imagens iniciais a partir da sobreposição de matrizes-negativos, abrindo-se a uma infinita variedade de impressões que podem ser produzidas a partir da incidência dos raios de luz.

A ideia para a construção da narrativa do trabalho fotográfico é eleger uma "imagem principal" (primeira camada das Figueiras do Laranjal), responsável por viabilizar a associação com outras informações visuais que irão compor o trabalho, que podem ser: imagens de arquivos de família e arquivos públicos de documentos da escravidão desta região. Acreditamos que esse processo seja similar ao do fotógrafo Eustáquio Neves, que se serve de fragmentos de vários negativos, cópias de imagens e informações verbais as quais ganham forma durante o processo criativo. A sobreposição de camadas na obra deste fotógrafo mediatizam a percepção, ao colocar a sua própria experiência de vida nelas com referência a memória e às questões raciais e sociais. Para romper com o paradigma de uma fotografia convencional Eustáquio Neves parte de uma "expansão da experiência do visível, 
não acredita apenas no registro da câmera fotográfica e produz uma imagem permeada por outras imagens que ampliam significamente nossa percepção". (FERNANDES JR, 2005, [s.p]).

Por fim, ressalto a importância deste estudo na contribuição para percepção de diferentes maneiras de trabalhar as relações entre os elementos de uma imagem fotográfica, com principal enfoque para o processo de criação e a reunião de fragmentos diversos para se criar uma imagem com o propósito de romper com uma fotografia que supervaloriza a captura da imagem. Assim, essa pesquisa tem por objetivo principal investigar a relação entre memória, fotografia e processo criador, pautada pela experimentação e pelo estudo aprofundado da técnica do cianótipo e como ele retorna à fotografia contemporânea. Pretende-se com isso ressignificar os primeiros registros realizados das Figueiras, nas ruas internas de areia da Praia do Laranjal, fazendo emergir novos discursos visuais por meio do contato com a materialidade, intervenções e desdobramentos através da técnica do cianótipo.

Nosso entendimento da pesquisa em artes encontra sua expressão em Lancri quando ele afirma que "uma tese em artes plásticas tem por originalidade entrecruzar uma produção plástica com uma produção textual; ela não se completa senão quando consegue ligá-las por traves" (LANCRI, 2002 p.19). Ela continua seu raciocínio afirmando que "o ponto de partida da pesquisa situa-se, contudo, obrigatoriamente na prática plástica ou artística do estudante, com o questionamento que ela contém e as problemáticas que ela suscita" (ibid p.20)

No entrecruzamento do trabalho visual e reflexivo que parte da prática artística, escolhemos a relação com a matéria estimulada pelo potencial criador como o elemento que conduz a pesquisa e que indica as abordagens metodológicas.
Essa relação com a matéria é um fazer constantemente em que o tempo se faz visível nas permanentes modificações das formas da materialidade das coisas. O formar como fazer, inventando o modo de fazer como diz Pareyson:

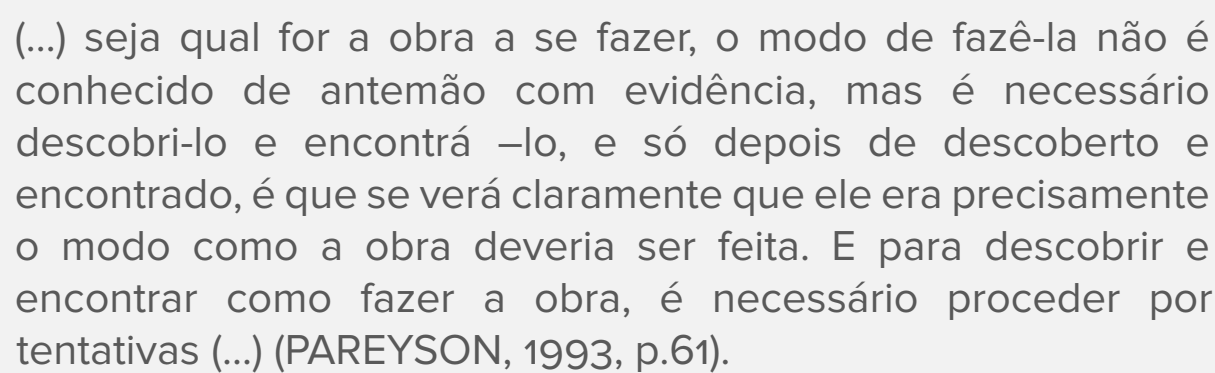

Na obra da qual tratamos neste artigo a prática e teoria andam juntas. Para Muller-Pohle (1985), fazer fotografia pressupõe uma série de intervenções em diferentes momentos: entre o artista e o objeto, dentre os procedimentos que poderão ser executados destacam-se, a produção de imagens por apropriações de outras imagens; entre o artista e o aparelho, enfatizando o lado subjetivo do fotógrafo e entre o artista e a imagem, interferindo na própria fotografia. Pode-se dizer que essa pesquisa passa por esse vários momentos.

Na primeira fase da pesquisa que pontuo como o primeiro semestre do Mestrado foram realizados registros fotográficos digitais das figueiras nas ruas internas do Laranjal em ângulos abertos, paralelamente junto a esses registros iniciais, documentei nos diários de criação e processo, as sensações, percepções e questionamentos sobre o ato fotográfico.

Os diários de criação podem ser entendidos como documentos de processo criativo, tal como proposto por Salles (2011), e podem ser utilizados como indicadores, uma forma de entender os tipos de relações que vão se estabelecendo com a geração da obra: "Os documentos de processo são, portanto, registros materiais do processo 
criador. São retratos temporais de uma construção que agem como índices do processo criativo" (Ibid. p.26). Por meio das estratégias para estudar os documentos de processo, procura-se conhecer os rastros de uma obra em construção e transformação, uma investigação processual. Essa abordagem, que Salles (2000) chama de Crítica de Processo Criativo, utiliza o percurso de criação para desmontá-lo e em seguida colocá-lo em ação novamente: "[...] o interesse desses estudos é o movimento criativo: o ir e vir da mão do criador" (lbid. p.23).

As ações concretas que dão existência à obra também são objeto desse estudo, assim é importante destacar que logo depois de realizados os registros fotográficos, para a primeira fase da pesquisa, foi iniciada a experimentação com o cianótipo, com o papel como suporte. O processo do cianótipo passa por várias etapas: produção da matriz-negativo, que atualmente pode ser feita com o software de edição Photoshop, a preparação dos químicos, a exposição ao sol, a revelação, viragem e tonalização. O hibridismo se dá na combinação dos métodos digital (produção de negativos) e o processo alternativo e artesanal com o cianótipo.

Nessa primeira fase também houve a apropriação de fotografias do arquivo de de minha avó. Experimento trabalhar com sobreposi ção de imagens. Em todas as imagens trabalhadas com o cianótipo nesta primeira fase da pesquisa foram feitas fichas catalográficas com a finalidade de sistematizar os dados do processo executado. Nelas são colocadas informações como superfície, mês, local, ano, químicos, o tempo de exposição, quantidade de químicos, luz e observações técnicas e subjetivas do processo.

Para a segunda fase da pesquisa foi realizada nova saída de campo para a realização dos registros das figueiras do Laranjal de ângulos mais fechados. Importava aqui as questões do tempo e suas manifestações na matéria. Também teve início uma pesquisa com os arquivos históricos da escravidão, na Biblioteca Pública de Pelotas, RS, com o levantamento de anúncios de vendas, compras de escravos do jornal Diário de Pelotas do século XIX, além de cartas de alforrias, atestado de batismo de escravos. A partir destes documentos percebe-se as relações que se estabeleciam entre os escravos, seus proprietários e a sociedade, naquela época. A preocupação com a escravidão está presente nesta pesquisa, mas somente será incorporada em outra fase deste trabalho.

Nesta segunda fase da pesquisa começo um estudo mais aprofundado da cor na cianotipia. A preocupação da cor trouxe necessidades de outras experimentações materiais e poéticas que serão abordadas em outro artigo mais detalhadamente.

Paralelamente às questões práticas, tanto na primeira como na segunda fase dessa pesquisa ampliou-se a revisão bibliográfica, com intuito de aprofundar o entendimento sobre a memória, o tempo, a fotografia expandida e as técnicas relacionadas à cianotipia. Ao mesmo tempo, foram analisados detalhadamente trabalhos que utilizam a imagem priorizando o processo criativo em suas formas híbridas, enfatizando os processos históricos de fotografia século, momento que foi enfocado especialmente o trabalho dos fotógrafos Eustáquio Neves, Cris Bierrenbach e Kenji Ota. Com isso se pretende dar maior densidade à proposta.

As primeiras imagens trabalhadas no processo criativo desta pesquisa são dos registros fotográficos realizados por Daniela Pinheiro das Figueiras nas ruas de areia da praia do Laranjal, bairro localizado a 12 quilômetros do centro da cidade de Pelotas, no estado do Rio Grande do Sul. Vindo de Pelotas em direção ao Laranjal é preciso atravessar uma ponte, onde localiza-se abaixo dela o Arroio Pelotas e as charqueadas em sua margem.

As fotografias para essa pesquisa foram realizadas nos anos 
de 2016 e 2017, em ambos os anos permaneci três meses nessa localidade, no período das férias de verão. Desde que mudei para São Paulo há oito anos atrás não tinha passado todo esse período, junto à minha família e a terra onde nasci.

O Laranjal é localizado à margem da Lagoa dos Patos, um lugar onde muitas famílias de Pelotas possuem suas casas de veraneio. Ali chegam no mês de dezembro e só voltam para a cidade no mês de abril, onde o frio começa a dar os seus primeiros sinais. A minha família é um desses casos, desde que nasci veraneio no Laranjal. Todas as ruas internas deste lugar são de areia, o que possibilita andar de bicicleta, sentindo a brisa que vem da lagoa e o tempo presente da paisagem no ar. o chiado das rodas de bicicleta é um som característico desse lugar. Pedalar por suas ruas, remete a uma sensação de deserto em que as figueiras centenárias marcam seu tempo em quase todas as esquinas.

Ao ficar mais tempo, sem pressa de voltar pude sentir novamente aquele lugar. Saia logo cedo, sozinha de bicicleta para pedalar por suas ruas. Esse movimento foi se repetindo, a tarde, à tardinha e a noite; quase todos os dias. Uma mochila atrás das costas e a câmera dentro dela. As figueiras centenárias olhavam para mim e eu para elas e ali ficava pensando o que elas queriam me dizer. Acabei indo fotografá-las, praticamente todos os dias. Com o GPS do celular, localizava as figueiras. Fui criando um mapa para não me perder delas, nem elas de mim.

Mas por que estudar a técnica do cianótipo usando as imagens das Figueiras do Laranjal? Fotografar essas ruas com as figueiras não se limita apenas à imagem das árvores e ao silêncio de suas ruas internas de areia ou a uma memória pessoal, pois envolve a paisagem que guarda, no entrelaçamento das raízes dessas árvores, a memória da história desse lugar, já que as figueiras são árvores nativas e antigas desta região - talvez elas sejam contemporâneas da própria descoberta do cianótipo. Que histórias invisíveis estão guardadas nelas? Há mais de 200 anos surge a cidade de Pelotas e o Laranjal, no tempo da exploração da mão de obra escrava, em que as charqueadas sustentavam a economia com o trabalho escravo. Ao trabalhar com a questão da memória o que se pretende é seguir, as sombras de um passado que é contemporâneo de um presente; ações que se referem a qualquer coisa que está além do que é visível. Perceber a duração como algo inseparável da memória (BERGSON, 2006) e a memória como vida, e esta, por sua vez, como criação contínua. Um passado/presente que busca dar espaço à matéria e possibilitar um caminho possível aos atos sensíveis.

Logo após as saídas fotográficas costumo registrar nos diários de criação e processo, as sensações, percepções e questionamentos sobre o ato fotográfico. Por não se configurar como linguagem definitiva os diários de criação e processo apresentamse como espaço para o possível, assumindo o papel que Salles (2011) destaca nos documentos de processo: armazenamento e experimentação. A situação de inacabamento evidenciada nesses diários mostram signos em estados de imprecisão, mas apontam alguns indícios do processo criativo. Por estar à criação em processo, revelam um movimento aberto aos possíveis devires " $\mathrm{Di}$ ários e anotações deixam as vezes que nos aproximemos do momento de desenvolvimento daquilo que o artista pretende dizer, ainda sem a roupagem que receberá da obra" (SALLES, 2011, p.80). Logo abaixo não coloco a escrita destes diários na íntegra, somente alguns questionamentos, apontamentos e percepções do período em que estava no Laranjal, em 2016, fotografando as figueiras, junto à câmera fotográfica: 
[...] no início a idéia era fotografar as figueiras e as ruas de areia da praia do Laranjal para experimentar com o cianótipo, mas agora não sei onde está o início porque quando fui fotografar uma das figueiras, já não as fotografei em um ângulo geral pois aquela árvore me convidava a estar nela; assim fui entrando aquela árvore me convidava a estar nela; assim fui entrando raízes, suas histórias. O tempo que agora não era só meu mas dela também.

Percebo que fotografar a partir dos ângulos mais fechado as figueiras é necessário tempo, um tempo de espera, um diálogo entre eu e a matéria. Para ela me presentificar precisa voltar em mim como sensação e sentir o tempo dela por suas marcas. Mas adentrando nas figueiras, depois de diversas sessões de fotografia comecei a perceber essas figueiras de outra forma. Assim, no ano de 2017 comecei a fotografar as mesmas figueiras em ângulos mais fechados. Começo a notar as questões do tempo e suas manifestações, imagens que carregam por si a marca da temporalidade da matéria. Um tempo que deixa vestígios, marcas, sinais de velhice como os anéis do tronco dessas velhas árvores. "Para os japoneses esses sinais de idade e passagem de tempo são chamados de "saba", que significa literalmente, "corrosão", um desgaste natural da matéria" (TARKOVSKI 1998, p.66). Vejo no meu trabalho com o processo de cianotipa esse tempo também. Coloco-me nas palavras de Kenji Ota:

Preferir a luz ambiente no fazer de sua fotografia, em um tempo e uma duração que e propria dele. O tempo de preparar o material, o tempo de expor, de esperar (...) uma escolha propria de querer fazer um trabalho com o tempo também. Não só a fotografia como o registro de alguma coisa no tempo, mas o processo a ser vivenciado (FERNANDES apud KENJI, 2002, p.222).

DARALEL@3I
Quando se está trabalhando com o cianótipo, entra-se em profunda sintonia com a matéria, surgindo vários pensamentos e questionamentos sobre a construção conceitual e prática do trabalho. Como comenta Bachelard (2008), é uma relação com a matéria profunda e intensa. O processo com o cianótipo passa por várias etapas: desde a produção da matriz-negativo no computador com o software de edição Photoshop, o preparamento dos suportes com a gelatina; a manipulação com os químicos; a gestualidade com o pincel, a exposição ao sol do negativo, a lavagem na bacia com água; a viragem e a tonalização. Toda essa espera inaugura um movimento ondulatório entre o momento da ação e o intervalo, "deixando aparente o ato criador como um projeto em processo" (SALLES, 2011, p. 68).

Saber interagir com a forca da matéria e, a partir dela, conduzir uma trajetória, uma linha; experimentar e me deixar levar pelos fluxos dos acontecimentos. Penso que o silêncio dessa espera é a escuta dos ruídos e a conexão entre meu processo e a narrativa de meu trabalho. Assim o processo com o cianótipo vai estabelecendo uma relação dialógica com o material, permitindo a vivência do que foi apontado por Pareyson:

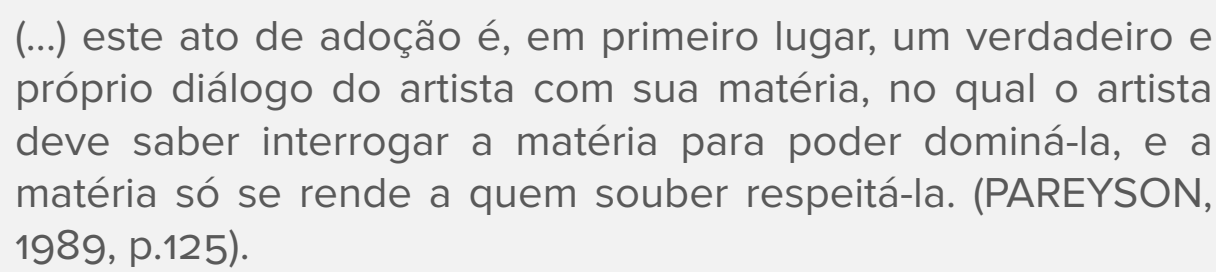

Depois de revelada as primeiras imagens em azul, no processo criativo para essa pesquisa foram feitas experiências de tonalizar as imagens com café, água oxigenada, chá, amonia, carbonato de sódio e erva-mate. A cada imagem materializada, nessas experimentações com o cianótipo começava a perceber elas de outra forma (Figura 1). 
Um retorno. Uma articulação entre os elementos conhecidos e os aspectos desconhecidos de um repertório ou de espaços estranhos, entrar e sair da zona de conforto, vislumbrar as possibilidades de criação e surpreender por meio da experiência da criação.

Retornei para a primeira camada. Voltei as figueiras, as raízes dessas árvores. Tive que pausar. Abrir caminho para os próximos questionamentos. A memória que aqui passa a ser pensada é a que faz de si própria processo que através da lembrança contamina o olhar do presente e é pelo presente contaminada "Em certo sentido, o passado é muito mais real, ou, de qualquer forma, mais resistente que o presente, o qual desliza e se esvai como areia entre os dedos" (TARKOVISKI, 1998, p.66)

Percebi que a cor que surgiu, durante o processo na primeira fase da pesquisa não me passava a sensação cromática das ruas de areia do Laranjal. Assim no outono de 2017 voltei ao Laranjal com o objetivo de recolher uma amostra de areia de suas ruas. Coloquei um pouco de areia em um potinho de vidro, para ter uma outra referência cromática deste lugar. Quando penso no Laranjal imediatamente me vem as ruas internas de areia e o momento vivido junto a elas, aquela imensidão de areia ... o tempo no ar dessas árvores ... da terra surgimos para terra voltamos.

Assim começo a experimentar com os próximos cianótipos com o objetivo de chegar a uma aproximação da informação cromática das ruas internas do Laranjal, sistematizando os dados técnicos na fichas catalográficas em um estudo mais aprofundado da cor, registrando detalhadamente o procedimento técnico envolvido no meu processo criativo. Além da cor azul pode-se também trabalhar com a tonalização de um cianótipo. É importante colocar aqui que ao tonalizar um cianótipo, segundo Kenji Ota, não implica absolutamente na geração de outro processo fotoquímico: "Não se pode levar ao pé da letra o nome ciano- azul. Quando se muda de cor não se renomeia o processo". (OTA, mensagem pessoal, 2016).

Para os experimentos com a cor no processo de cianótipia, opto por utilizar a mesmo negativo (matriz), trabalhando com o tecido de algodão cru, pois futuramente a intenção é bordar essas imagens. Optei por continuar experimentando tonalizar as imagens com erva-mate, na segunda fase da pesquisa, por esse elemento carregar um caráter simbólico, no seu contexto. O chimarrão é uma bebida característica da cultura do sul da América do Sul legada pelas culturas indígenas. Na cidade de Pelotas é uma bebida tradicional de sua cultura.

Através desses experimentos com a cor pela tonalização e viragem do cianótipo percebe-se que ainda que utilizada a mesma fonte de luz, o mesmo tempo de exposição e suportes como a mesma características, mas com proporções dos elementos químicos diferentes entre si, obtém-se resultados cromáticos distintos em relação a saturação da cor (Figura 3). O horário e o tempo de exposição ao sol, o tempo do cianótipo na bandeja com erva-mate e água quente, a viragem com o carbonato de sódio, influenciam na cor do cianótipo em relação às três principais propriedades da cor: matiz, claridade e saturação.

É importante colocar aqui que o processo com o cianótipo se transforma em longas horas até atingir o resultado esperado "(...) a rapidez dá lugar a horas, dias e semanas... inúmeras são as tentativas durante o espaço de tempo" (BRACHER, 2016 p.101). Assim torna-se fundamental anotar todas as informações técnicas, nas fichas catalográficas para sistematizar os dados do 


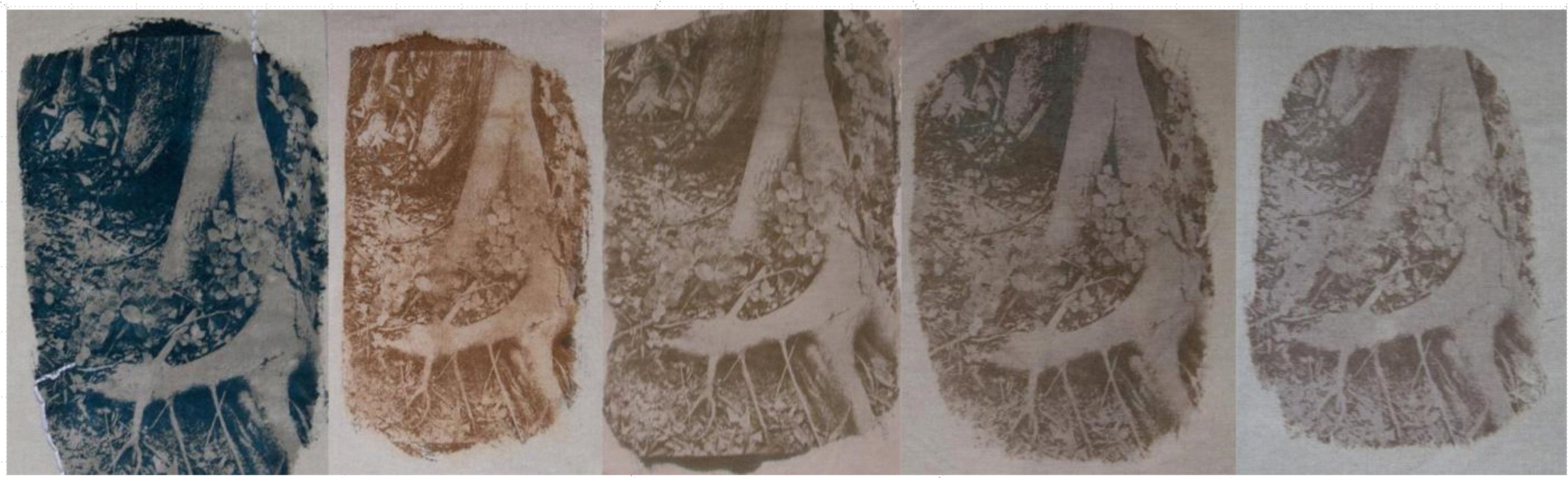

Figura 3 - Daniela Pinheiro

Estudo da cor no processo com o cianótipo sobre tecido, 2017.

processo executado com o objetivo de desenvolver um estudo mais aprofundado da cor.

Para Sennet (2009), sentimento e pensamento são tornados possíveis ao homem por meio do fazer, pela mediação que atividade material oferece. É como vejo o meu trabalho: algo prolongado, carregado de significados no seu caminho; onde a prática anda junto à escrita, no seu processo criativo. Um trabalho em construção, onde perpassa uma atividade material, prática e artesanal entre: mente $\mathrm{x}$ corpo, pensamento $\mathrm{x}$ ação, concepção $x$ execução, teoria x prática.

Durante o processo de criação junto às leituras e a escrita foram percebidos os passos a serem seguidos a partir de agora com a pesquisa. Trabalhando com a sobreposição noto que a natureza da imagem se altera, gerando uma nova experiência para o olhar. Para que a matéria possa ser modelada em seu devir, é preciso que ela seja, diz Simondon (apud PELBART, 2010, p.48), como a "argila no momento em que é pressionada no molde, realidade deformável, isto é, realidade que não tem uma forma definida, mas todas as formas indefinidamente, dinamicamente".

Pode-se pensar nos registros iniciais das Figueiras do Laranjal como uma primeira camada de um novo corpo, de uma nova imagem a ser formada por acúmulo com outras imagens. Através do cianótipo e da materialidade proporcionada por essa 
técnica é possível pensar em uma desestabilização da imagem. $\mathrm{Na}$ segunda camada trabalhada com as imagens do arquivo de minha avó sobrepostas com a primeira camada (imagem da Figueira) percebe-se que poderia ser interessante retirar alguma parte dessa imagem ou também compor com outros elementos imagéticos de uma terceira, quarta, quinta imagem que podem aqui serem inseridos os documentos da escravidão e arquivos de família.

Percebe-se nesse trabalho uma proximidade com o conceito de rizoma de Deleuze e Guatarri, para eles o rizoma é "um mapa e não decalque, já que o mapa é aberto, conectável em todas as suas dimensões, desmontável, reversível, suscetível de receber modificações constantemente" (DELEUZE, GUATTARI, 1995, p. 22). A idéia é montar um grande mapa de memórias atemporais. Um labirinto sem começo nem fim, sem centro e periferia, uma estrutura de passagem feito de atalhos e desvios e encontros imprevistos. Linhas de fuga que permitem "explodir os estratos, romper as raízes e operar novas conexões" (DELEUZE, GUATTARI, 1995, p.24). Para Deleuze e Guatarri (1995), uma das características mais importantes do rizoma talvez seja a de ter sempre múltiplas entradas.

Esse tempo de processo em que esta pesquisa se constitui não tem um antes e depois. Interessa assim investigar as questões do tempo, da memória e suas manifestações na matéria fotográfica, aonde a materialização vai se dar com a experimentação da técnica de cianótipo, não se fechando a possíveis manipulações nos negativos através do software Photoshop para dar corpo as camadas a serem trabalhadas. Acreditamos criar um diálogo com os sinais do tempo na escolha das imagens de ângulos mais fechados das figueiras, onde é sentido uma duração fluindo em diferentes freqüências, "uma pluralidade de ritmos, de durações que se superpõem em profundidade, com níveis de tensão distintos". (LAPOUJADE, 2013, p. 11).

Pelbart em seu livro "O tempo não reconciliado" se questiona sobre a imagem em movimento no tempo perguntando: Como pode a própria imagem, um mesmo plano, independente da montagem comportar a força do tempo? Segundo ele foi Tarkovski (2010) quem melhor formulou o problema "o tempo deve fluir na imagem, cabe mostrar a pressão do tempo no plano, sua tensão ou rarefação". (TARKOVSKI apud PELBART, 2010, p. 3). Como pensar esse tempo quando se trabalha com uma imagem fotográfica em uma superfície plana? Resolver em uma só imagem através de camadas de imagens/memórias sem precisar utilizar outra linguagem como o vídeo, a instalação artística é possível? Esse será o grande desafio para os passos a serem seguidos com essa pesquisa. Penso que talvez essa dimensão se manifeste na relação entre uma imagem e outra, entre elas, onde uma passa deixando vestígios sobre as outras, criando assim um movimento na superfície plana.

\section{REFERENCIAS BIBLIOGRÁFICAS}

BACHELARD, Gastón. A terra e os devaneios da vontade. São Paulo: Martins Fontes, 2008.

BRACHER, Andréa. O Espírito dos Sais: Luiz Eduardo Robinson Achutti e seu trabalho artístico com processos fotográficos alternativos. Revista Gama, Estudos Artístico da Faculdade de Belas Artes de Lisboa, Portugal, ano 4, n.7. p.96- 103,janeiro 2016. Inclui índice. ISSN 2182-8539, e-ISSN 2182-8725.

BERGSON, Henri. Matéria e Memória: ensaio sobre a relacão do corpo com o espírito. Traducão Paulo Neves. 3 ed. São Paulo: Martins Fontes, 2006. 
CHIARELLI, Tadeu. A arte internacional brasileira.

2.ed. São Paulo: Lemos Editorial, 2002.

DELEUZE, Gilles; GUATARRI, Félix. Mil platôs: capitalismo e

esquizofrenia. Vol.4 Traducão de Suely Rolnik. São Paulo: 34, 1997.

Mil platôs: capitalismo e esquizofrenia. Tradução d Auréio Guerra e Célia Pinto Costta. Rio de Janelro: 34, 1995.

FERNANDES,JR,Rubens. A fotografia expandida. Tese

(Doutorado em Comunicacão e Semiótica) - Pontifícia

Universidade Católica de São Paulo, São Paulo, 2002.

Processos de Criacão na Fotografia: apontamentos para o

entendimento dos vetores e das variáveis da produção fotográfica. FACOM,

n.16, p.10-19, 2.setem 2006.Disponivel em: <http://www.faap.br/revista_

faap/revista_facom/facom_16/rubens.pdf>. Acesso em: 20 set. 2006.

Anatomia do Fragmento de Rubens. In: NEVES,

Eustáquio. Fotoportátil. São Paulo: Cosac Naify, 2005.

FLUSSER, Vilém. Filosofia da caixa preta: ensaios para uma futura filosofia da fotografia. Traducão do autor. Rio de Janeiro: Relume Dumará, 2002.

LAPOUJADE, David. Potências do tempo. São Paulo: n-1 Edições, 2013.

LANCRI, Jean. Modestas proposições sobre as condições de

uma pesquisa em artes plásticas na universidade. 0 meio como

ponto zero: metodologia de pesquisa em artes plásticas. 1.

ed. ed., p.17-33, 2002. Porto Alegre: Ed. da UFRGS.

MONFORTE, Luiz Guimarães. Fotografia pensante. São Paulo: SENAC, 1997.

MULLER-POHLE, Andréas. Information Strategies.

Revista European photography, v.6, n.1, 1985 .

OTA, Kenji. Entrevista concedida a Daniela Pinheiro.

[E-mail]. São Paulo, 26 nov. 2016

OSTROWER, Fayga. Criatividade e processos de

criacão 4 ed Petrópolis: Vozes 1984.

PAREYSON, Luigi. Os problemas da estética. São Paulo: Martins Fontes, 1989.

Estética: teoria da formatividade. Tradução
Ephraim Ferreira Alves. Petrópolis, RJ: Vozes, 1993

PELBART, Peter. O tempo não-reconciliado. São Paulo: Perspectiva, 2010.

ROUILLÉ, André. A fotografia: entre documento e arte contemporânea.

Traducão Constancia Egrejas. São Paulo: SENAC, 2009.

SALLES, Cecília Almeida. Gesto inacabado: processo de criacão artística. 5. ed.São Paulo: Intermeios, 2011.

A fotografia no contexto da experimentacão contemporânea. Discursos Fotográficos, n.19, p.169-19o, jul/dez 2000. Disponíve em: <http://www.uel.br/revistas/uel/index.php/discursosfotograficos/ article/view/20972>. Acesso em: 28 nov. 2016.

SEIXAS, Jacy Alves. Percursos de memórias em terras de história:problemáticas atuais. In: BRESCIANI, Stella; NAXARA, Márcia (Org.). Memória e (res)sentimento: indagações sobre uma questão sensível. Campinas,SP: Unicamp: 2004.

SENNET, Richard. 0 artífice. Traducão Clóvi Marques.

2. ed, Rio de Janeiro: Records,2009.

TARKOVSKI, Andrei. Esculpir o tempo. Traducão Jefferson

Luiz Camargo 2 ed São Paulo: Martins Fontes, 1998. 